\title{
Simplified cascade multiphase DC-DC buck power converter for low voltage large current applications: part II --- output current controller
}

\author{
Nungky Prameswari, Anand Bannet Ganesen, Falah Kharisma Nuraziz, Jihad Furqani, Arwindra \\ Rizqiawan, Pekik Argo Dahono \\ Department of Electrical Engineering, School of Electrical Engineering and Informatics, Institute of Technology
}

Bandung, Bandung, Indonesia

\section{Article Info \\ Article history: \\ Received May 27, 2021 \\ Revised Sep 22, 2021 \\ Accepted Sep 29, 2021}

Keywords:

Buck

Cascade

Cathodic protection

Control

Multiphase

\begin{abstract}
This paper proposes a control method for new simplified cascade multiphase direct current-direct current (DC-DC) buck power converters used for lowvoltage large-current applications such as cathodic protection. To control the proposed converter, a proportional-integral (PI) controller is used to regulate the output current of the converter. The control scheme analysis is carried out by linearizing the small-signal model of the proposed converter to form the output current transfer functions. This transfer function will be analyzed by using phase and gain margin approach to obtain the control parameters (Kp, $\mathrm{Ki}$, and $\mathrm{Ti}$ ). Simulation and experiment results are included to show the validity of the proposed concept.
\end{abstract}

This is an open access article under the $\underline{C C B Y-S A}$ license.

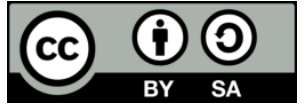

\section{Corresponding Author:}

Nungky Prameswari

Department of Electrical Engineering, School of Electrical Engineering and Informatics

Institute of Technology Bandung

Ganesha St. No. 10, Bandung 40132, Indonesia

Email: nungkyprameswari24@gmail.com

\section{INTRODUCTION}

Corrosion is one of the destructive phenomena or deterioration of the quality on both metallic or non-metallic materials due to the interaction between the materials with the surrounding environment [1]. This corrosion process usually occurs to materials that buried in the ground, such as pipe line for oil and gas industry. There are many ways to overcome the corrosion of metal, cathodic protection is one of them. Cathodic protection is divided into two methods, sacrificial anode method and impressed current method [2].

This study, the discussion is focus on the impressed current method. This method injects direct current which is derived from a single-phase alternating current (AC) source through a full bridge diode rectifier and a step-down DC-DC converter. The negative output pole of the DC-DC converter will be connected to the metal underground, which functions as a cathode, and the positive pole will be connected to a metal consisting of a certain material that will be functioned as an anode. Later, the anode metal will supply the impressed current from the DC power supply to the cathode [3]. The step-down DC-DC converter for this purpose must have a very low voltage-ration and large current with very low output current ripple [4], [5]. In order to meet those requirements, a new simplified cascaded multiphase topology which has high voltage reduction ratio and large output currents with low ripple is proposed in Part I [6]. It should be noted that this converter is the dual of the converter that has been proposed in [7]. 
Apart from specifications, the important part in DC-DC converters is how to design the controller by defining a dynamic model of the system [8]. There are many different modeling techniques namely small signal and large signal modeling techniques that have been proposed to describe the dynamics of a buck converter. From this technique, the state-space average is the most acceptable way to obtain the small signal transfer function of the DC-DC converters [8]-[13].

For physical implementation, a suitable controller must be used to obtain stable-controlled DC-DC power converters to supply the current needed for the load with low sensitivity against various disturbances. This is also what the proposed topology requires, namely a simple and reliable controller even though the system is non-linear. There are several non-linear and linear control techniques that have been discussed in the literature to ensure that the buck converters can work properly when various disturbances are given [14][17]. The nonlinear control techniques such as $\mathrm{H}-\infty$ and sliding mode control are successful in controlling the buck converter, but electromagnetic interference (EMI) and mathematical complexities are become the other issues of those techniques [18]. Other nonlinear control techniques such as fuzzy and one-cycle control also have limitations, namely the fuzzy method is considered unable to provide better small signal response than standard regulators and one cycle control is considered capable of causing large harmonic current distortion [19]-[21]. In the other hand, linear control techniques such as PI/proportional-integral-derivative (PID) are controllers that are considered quite simple, easy to implement, and suitable for achieving system performance and stability. This is evidenced by the many applications in the industry that use this controller [22]-[24].

This paper proposes a control method for a new simplified cascade multiphase DC-DC buck converter that designed for low voltage large current application such as cathodic protection, which uses single loop proportional-integral (PI) to control the output current of the converter. The control scheme analysis is carried out by linearizing the small-signal model of the proposed converter to form the output current transfer functions. Simulation and experiment results are included to prove the performance of the control system against the various disturbances that are given.

The paper is organized is being as. In section 2, the dynamic modeling of a new simple cascade multiphase DC-DC buck power converter is derived. Section 3 will discuss current controller design for the proposed topology. Then, section 4 and section 5, respectively present the simulation and experimental results to validate the performance of the proposed controller. Finally, conclusions are offered in section 6 .

\section{DYNAMIC MODELING OF NEW SIMPLIFIED CASCADE MULTIPHASE DC-DC BUCK POWER CONVERTER}

According to the optimization that has been done in Part I, it can be shown that the topology as shown in Figure 1 is the optimal one. This is a simplified two-stage four-phase DC-DC buck converter. The basic principle of this converter can be explained as the following.

If one of the switches is ON (for example is $S_{1}$ ), the other switches are in the OFF state and the $D_{\mathrm{ON}}$ diode and all secondary diodes except $\mathrm{D}_{\mathrm{SEC} 1}$ will be forward biased, while the other diodes will be reverse biased. From this mechanism, current will flow in two directions: from DC source $\mathrm{E}_{\mathrm{d}}$ to the primary inductor $\mathrm{L}_{\mathrm{P}}$ and from diode $\mathrm{D}_{\mathrm{ON}}$ to capacitor $\mathrm{C}$. Then, both currents will add up and charge inductor $\mathrm{L}_{\mathrm{S} 1}$, before reaching the load and the other secondary inductors will discharge its current to the load. And the second mechanism is when all of the switches are OFF, where all diodes $D_{\text {OFF }}$ and secondary diodes will be forward biased and diodes $D_{\text {ON }}$ will be reverse biased. From this mechanism, the load will only receive discharged currents from the secondary inductors. Those two mechanisms also apply alternately to other switches. As the output side is a four-phase buck converter, the output current capability is large and the ripple content will be very low. Under continuous conduction mode, the average output voltage ratio is shown in (1), where $V_{o}$ and $E_{d}$ are the output and input voltages of the converter, respectively.

$$
\frac{V_{o}}{E_{d}}=4 \alpha^{2}
$$

with

$$
\alpha=\frac{T_{O N}}{T_{S}}
$$

is the duty cycle of switching devices with a maximum value of $0.25, T_{O N}$ is the ON-time of transistors and $T_{S}$ is the switching period of the transistor. 
In (1) shows that a very low output voltage can be obtained without using a very low duty cycle. For two-stage converter, it can be seen that the output voltage is proportional to the square of duty cycle. The output current is controlled by using a current controller as shown in Figure 1.

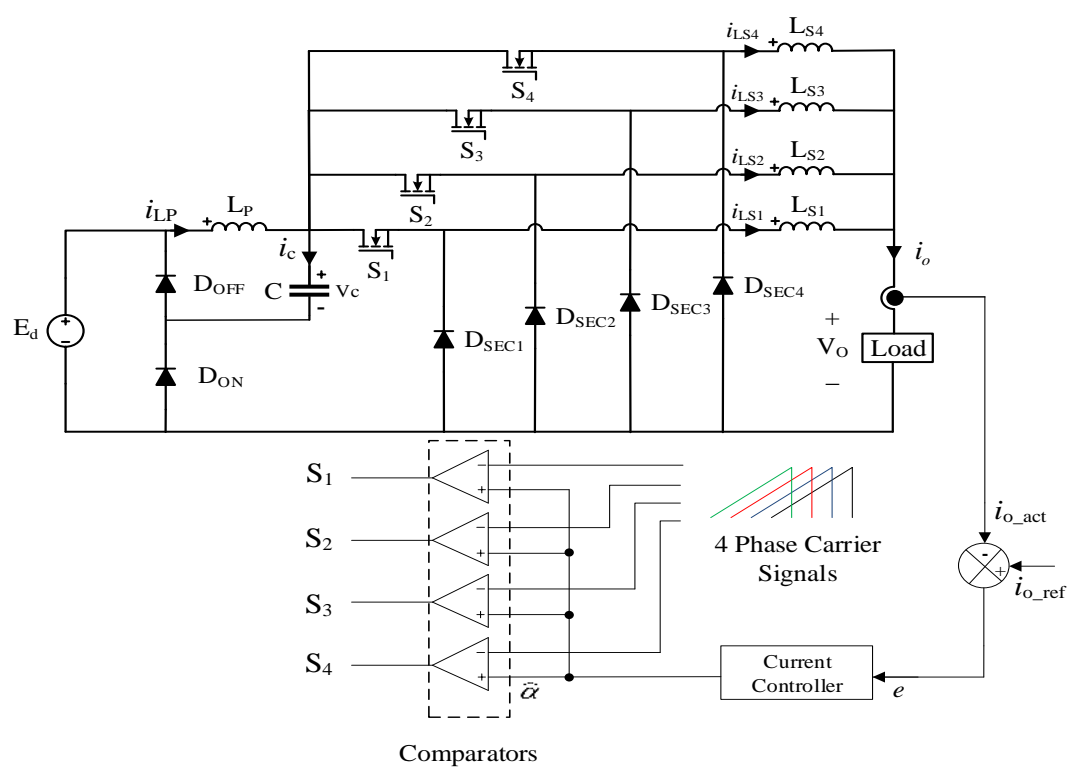

Figure 1. New simplified two-stages four-phase converter with current controller

To design the closed loop system, we should model the system in Figure 1 into the small-signal model. The first step is state space averaging process. Under continuous conduction mode, we can determine the state-space equation of converter when a transistor in four-phase buck converter receives an ON signal and state-space equation when all transistors receive OFF signals. The state space equation for those two conditions is written in (3) and (4).

$$
\begin{aligned}
& \dot{X}=A_{o n} X+B_{o n} Y \\
& \dot{X}=A_{\text {off }} X+B_{\text {off }} Y
\end{aligned}
$$

Where

$\mathrm{X}=$ state space variables (primary inductor current $\left(I_{L P}\right)$, output current $\left(I_{o}\right)$ and capacitor voltage $\left(V_{c}\right)$, $\mathrm{Y}=$ input variable (input voltage $\left(E_{d}\right)$ ),

$\mathrm{A}_{\mathrm{on}}$ and $\mathrm{B}_{\mathrm{on}}=$ state space matrix while switches are $\mathrm{ON}$, and

$\mathrm{A}_{\text {off }}$ and $\mathrm{B}_{\text {off }}=$ state space matrix while switches are OFF.

Based on (3) and (4), we can determine the average state-space in one switching period. Based on the converter in Figure 1, where $R$ represents the load of the converter. It can be shown that the following state-space equation can be obtained.

$$
\frac{d}{d t}\left[\begin{array}{c}
\bar{i}_{L P} \\
\bar{i}_{o} \\
\bar{v}_{C}
\end{array}\right]=\left[\begin{array}{ccc}
0 & 0 & -\frac{1}{L_{P}} \\
0 & -R\left(\frac{1}{L_{S 1}}+\frac{1}{L_{S 2}}+\frac{1}{L_{S 3}}+\frac{1}{L_{S 4}}\right) & \left(\frac{1}{L_{S 1}}+\frac{1}{L_{S 2}}+\frac{1}{L_{S 3}}+\frac{1}{L_{S 4}}\right) \alpha \\
\frac{1}{C} & -\frac{\alpha}{C} & 0
\end{array}\right]\left[\begin{array}{c}
\bar{i}_{L P} \\
\bar{i}_{o} \\
\bar{v}_{C}
\end{array}\right]+\left[\begin{array}{c}
\frac{4 \alpha}{L_{P}} \\
0 \\
0
\end{array}\right] E_{d}
$$

As a function of duty cycle $\alpha$ the above state space equation is nonlinear. To linearize the system, it is assumed that the duty cycle of transistor can be written as.

$$
\alpha=\bar{\alpha}+\tilde{\alpha}
$$


where bar and tilde over the variables represent the average and the small-signal quantities. Substituting (6) into (5) and takes the small-signal parts then the following small-signal equation can be obtained:

$$
\frac{d}{d t}\left[\begin{array}{c}
\tilde{i}_{L P} \\
\tilde{i}_{o} \\
\tilde{v}_{C}
\end{array}\right]=\left[\begin{array}{ccc}
0 & 0 & -\frac{1}{L_{P}} \\
0 & -\frac{R}{L_{T}} & \frac{\bar{\alpha}}{L_{T}} \\
\frac{1}{C} & -\frac{\bar{\alpha}}{C} & 0
\end{array}\right]\left[\begin{array}{c}
\tilde{i}_{L P} \\
\tilde{i}_{o} \\
\tilde{v}_{C}
\end{array}\right]+\left[\begin{array}{c}
\frac{4 E_{d}}{L_{P}} \\
\frac{V_{C}}{L_{T}} \\
-\frac{I_{o}}{C}
\end{array}\right] \tilde{\alpha}
$$

where

$$
\frac{1}{L_{T}}=\frac{1}{L_{S 1}}+\frac{1}{L_{S 2}}+\frac{1}{L_{S 3}}+\frac{1}{L_{S 4}}
$$

Based on (7), the open loop transfer function of output current as a function of duty cycle can be obtained as shown in.

$$
\frac{\tilde{I}_{o}(s)}{\tilde{\alpha}(s)}=\frac{L_{P} C V_{C} s^{2}-L_{P} I_{o} \bar{\alpha} s+4 \bar{\alpha} E_{d}+V_{C}}{L_{P} L_{T} C s^{3}+L_{P} C R s^{2}+\left(L_{T}+L_{P} \bar{\alpha}^{2}\right) s+1}
$$

If we plot (9) with the certain values to frequency response curve, we will obtain the phase margin (PM) and $\boldsymbol{\omega}_{\mathrm{c}}$ of the system without controller. These values will be used to calculate the control parameters.

\section{CURRENT CONTROLLER DESIGN}

In this research, a conventional proportional-integral (PI) controller is used to regulate the output current of the converter. The block diagram of the system under PI current controller is represented in Figure 2. The sensor gain, $H(s)$ is equal to unity if the sensor is ideal. The transfer function of the PI controller is defined by (10), where $K_{\mathrm{p}}$ and $K_{i}$ are the proportional and integrator gains, respectively.

$$
K_{p}+\frac{K_{i}}{s}=\frac{K_{p}\left(s+\frac{K_{i}}{K_{p}}\right)}{s}
$$

Therefore, the relation between output current to the reference output current using a PI controller can be represented by (11).

$$
\frac{\tilde{I}_{o}}{\tilde{I}_{o}-r e f}=\frac{\left(\frac{K_{p}\left(s+\frac{K_{i}}{K_{p}}\right)\left(L_{P} C V_{C} s^{2}-L_{P} I_{o} \bar{\alpha} s+4 \bar{\alpha} E_{d}+V_{C}\right)}{s\left(L_{P} L_{T} C s^{3}+L_{P} C R s^{2}+\left(L_{T}+L_{P} \bar{\alpha}^{2}\right) s+1\right)}\right)}{1+\left(\frac{K_{p}\left(s+\frac{K_{i}}{K_{p}}\right)\left(L_{P} C V_{C} s^{2}-L_{P} I_{o} \bar{\alpha} s+4 \bar{\alpha} E_{d}+V_{C}\right)}{s\left(L_{P} L_{T} C s^{3}+L_{P} C R s^{2}+\left(L_{T}+L_{P} \bar{\alpha}^{2}\right) s+1\right)}\right)}
$$

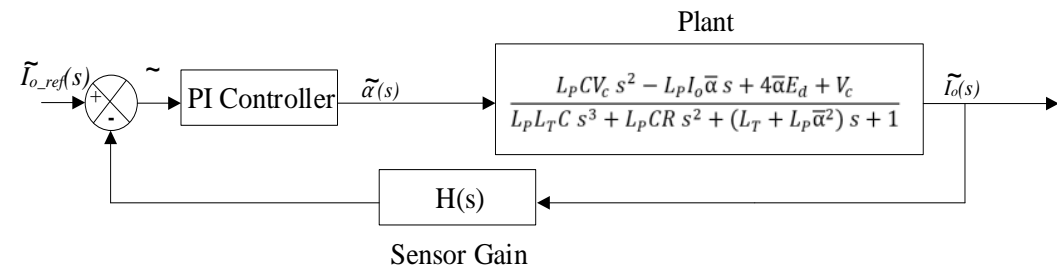

Figure 2. Block diagram of the system 
For determining the current control parameters, $K_{p}$ and $K_{i}$, we can use a commonly procedure by using a frequency response curve analysis to determine the crossover frequency of the system which is able to increase the gain at low frequencies while maintaining a positive PM [25]-[28]. In this study, system parameters as shown in Table 1 are used, where the values of components such as inductors and capacitors are obtained based on calculations to achieve continuous conduction mode (CCM). These parameters are the ones used in Part I of this paper. By substituting (11) with the parameters in Table 1 and adjusting it to the gain and phase margin requirements, the followings PI parameters are obtained as shown in Table 2 . Then, if we substitute (12) with the parameters in Tables 1 and 2, we will get the the bode plot diagram of the current controller using PI as shown in Figure 3. It is shown that up to $200 \mathrm{~Hz}$, the gain of the actual output current against the reference current is still unity. Although at $200 \mathrm{~Hz}$, there is a slight phase shifting between the actual current and the reference current $\left(-1.79^{\circ}\right)$.

Table 1. Converter design parameters

\begin{tabular}{ll}
\hline \multicolumn{1}{c}{ Parameter } & \multicolumn{1}{c}{ Value } \\
\hline Input Voltage $\left(E_{d}\right)$ & $100 \mathrm{Volt}$ \\
Inductor $\left(L_{s l}\right)$ & $1.03 \mathrm{mH}$ \\
Inductor $\left(L_{s 2}\right)$ & $1.03 \mathrm{mH}$ \\
Inductor $\left(L_{s 3}\right)$ & $1.03 \mathrm{mH}$ \\
Inductor $\left(L_{s 4}\right)$ & $1.03 \mathrm{mH}$ \\
Inductor $\left(L_{P}\right)$ & $2.6 \mathrm{mH}$ \\
Capacitor $(C)$ & $470 \mu \mathrm{F}$ \\
Nominal Load Resistance $(R)$ & $0.2 \mathrm{ohm}$ \\
Duty Cycle $(\bar{\alpha})$ & 0.095 \\
\hline
\end{tabular}

Table 2. Current control parameters

\begin{tabular}{cc}
\hline Parameter & Value \\
\hline$K_{p}$ & 0.0843 \\
$K_{i}$ & 631.83 \\
$T_{i}$ & $1.334 .10^{-4}$ \\
\hline
\end{tabular}

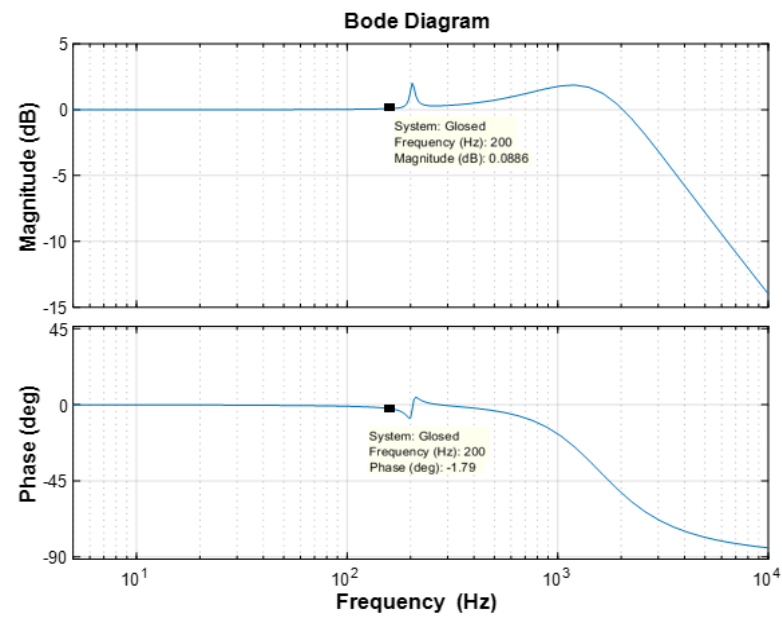

Figure 3. Bode plot diagram of actual output current against a reference output current

\section{SIMULATION RESULTS}

A new simplified two-stages four-phase DC-DC Buck converter with parameters as shown in Table 1 was simulated. The previous PI controller parameters were used.

\subsection{Case I: current reference variation}

In this case, the effect of the current reference variation is simulated with the results shown in Figures 4 (a) and (b). Figure 4 (a) shows the simulation result of the actual output current $\left(\mathrm{I}_{\mathrm{o}}\right.$ Actual) when reference output current $\left(\mathrm{I}_{\mathrm{o}} \_\right.$Reference) is changed from $22 \mathrm{~A}$ to $16 \mathrm{~A}$ at $\mathrm{t}=0.166 \mathrm{~s}$ and back again to $22 \mathrm{~A}$ at $\mathrm{t}=0.333 \mathrm{~s}$. It can be seen that the controller can maintain the actual output current when the reference output current changes in step variations with a fast response, as it only takes 0.003 and 0.005 seconds to achieve steady state under these 
changes. Figure 4 (b) shows the simulation results of the actual output current $\left(\mathrm{I}_{0} \_\right.$Actual) when the current reference $\left(\mathrm{I}_{\mathrm{o}}\right.$ Reference) contains $\mathrm{AC}$ component. It can be seen that the actual output current still can follow the reference output current up to $200 \mathrm{~Hz}$. But, at $200 \mathrm{~Hz}$, the phase between the actual current and the reference current starts to shift, the same as predicted by the Bode plot in Figure 3. Based on this result, it can be concluded that the dynamic modeling of the system is accurate and the controller is considered to work well in this case.

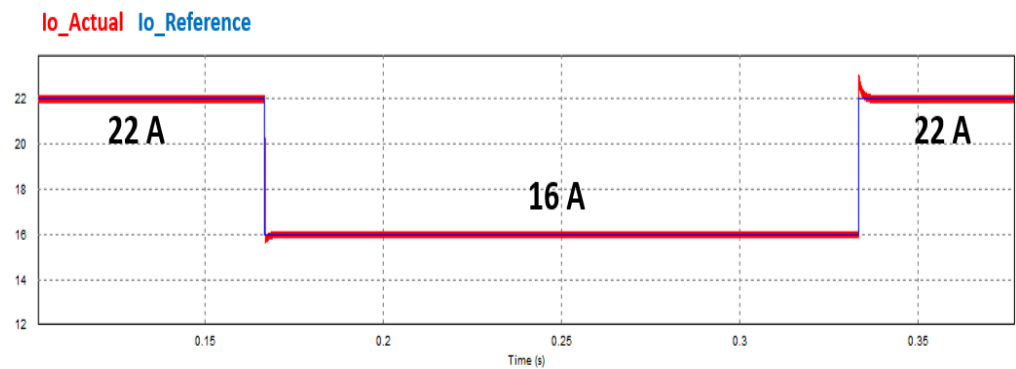

(a)

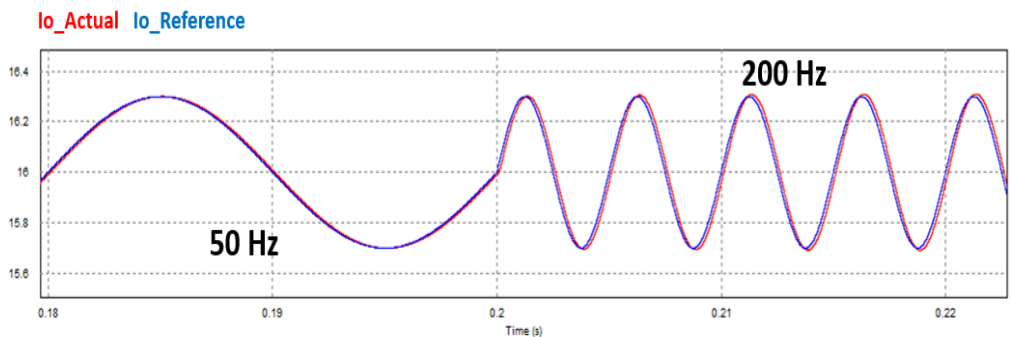

(b)

Figure 4. Simulation results for the reference current variation: (a) step changes, (b) AC components included

\subsection{Case II: variation in the load resistance}

In this case, the effect of load resistance variation is analyzed, to prove that the variation in the load does not affect the controlled output current. Figure 5 shows the simulation result of the actual output current $\left(\mathrm{I}_{\mathrm{o} \_}\right.$Actual) when the load changes from 0.2 to $0.1 \Omega$ at $\mathrm{t}=0.166 \mathrm{~s}$ and back again to $0.2 \Omega$ at $\mathrm{t}=0.333 \mathrm{~s}$. It can be seen that the controller can maintain the actual output current when the the load changes in a fast response (only $0.002 \mathrm{~s}$ ).

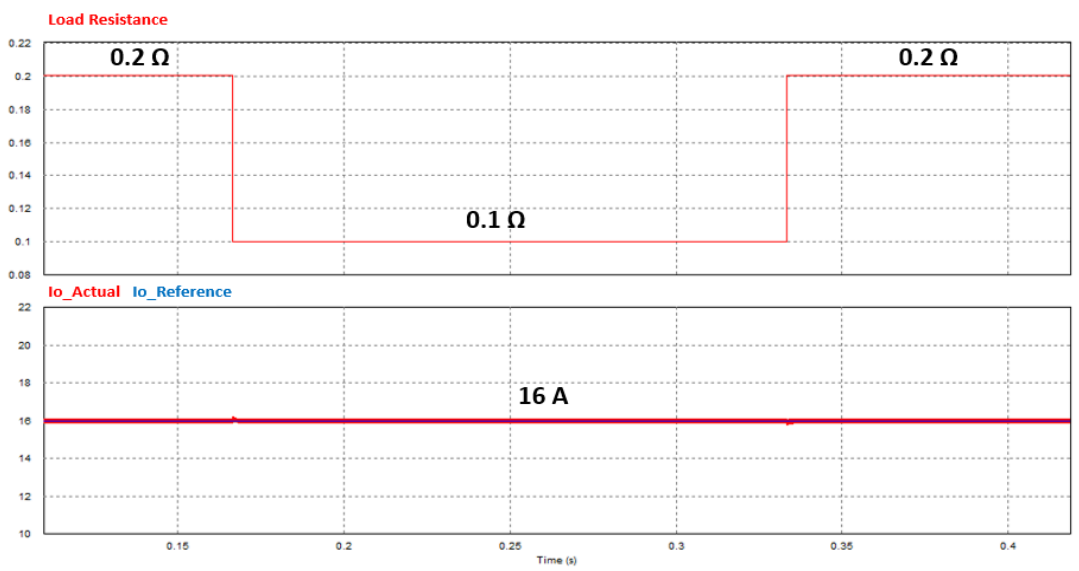

Figure 5. Simulation result for the load resistance variation

\subsection{Case III: variation in the source voltage}

In this case, the effect of source voltage variation is analyzed as depicted in Figures 6 (a) and (b). Figure 6 (a) shows the simulation results of the actual output current ( $\mathrm{I}_{\mathrm{o}}$ Actual) when the input voltage (Ed) 
is suddenly changed from 102 to $100 \mathrm{~V}$ at $\mathrm{t}=0.166 \mathrm{~s}$, and from 100 to $102 \mathrm{~V}$ at $\mathrm{t}=0.33 \mathrm{~s}$. Whereas Figure 6 (b) shows the simulation results of the actual output current ( $\mathrm{I}_{\mathrm{o} \_}$Actual) when the source voltage fluctuates due to a non-ideal source. It appears that the controller can maintain the desired output current properly when the input voltage changes, because the actual current still can follow the reference current pattern.

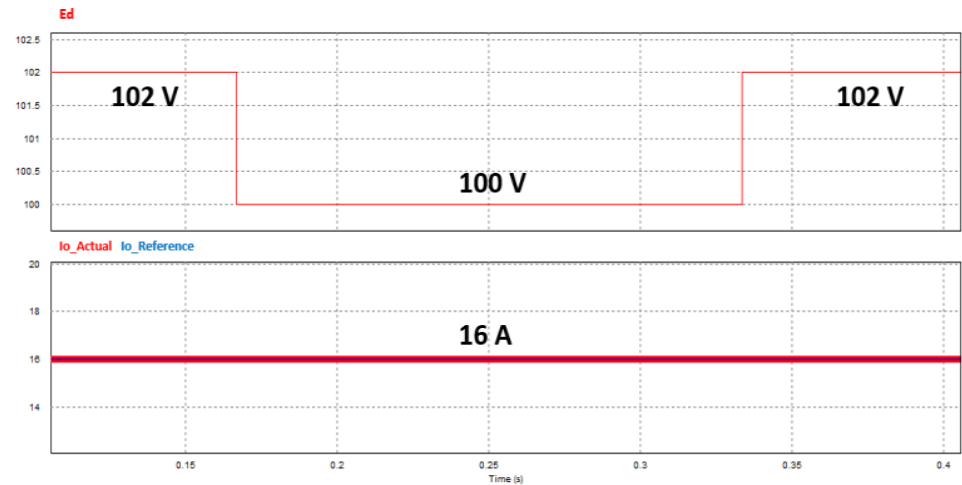

(a)

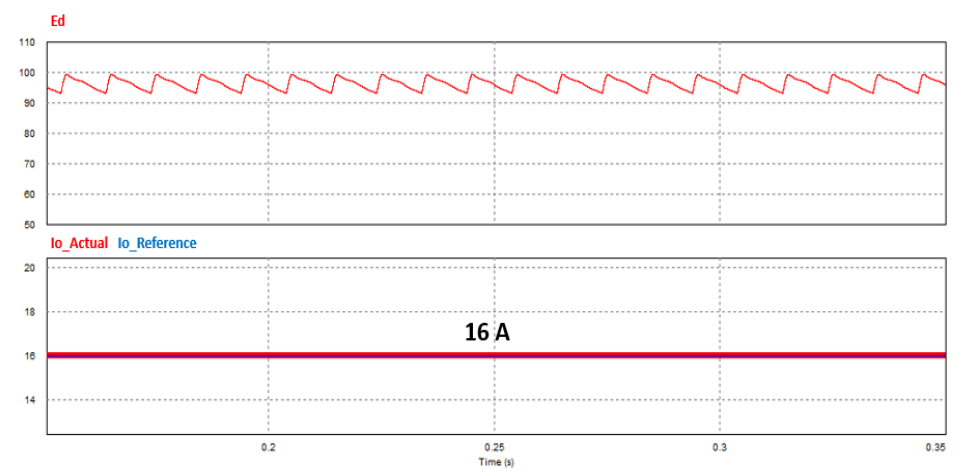

(b)

Figure 6. Simulation results for the source voltage variation: (a) step changes, (b) periodic fluctuation

\section{EXPERIMENTAL RESULTS}

In order to verify the validity of the proposed converter under current controller, several experiments were conducted. The scheme in Figure 1 is experimented as shown in Figure 7 with an input voltage of $100 \mathrm{~V}$ and a load with a resistance value of $\pm 0.2 \Omega$. The primary inductor $\left(L_{P}\right)$ has an inductance of $2.6 \mathrm{mH}$ with an internal resistance of $0.9 \Omega$, while the secondary inductor in each phase $\left(L_{S 1}, L_{S 2}, L_{S 3}\right.$, and $L_{S 4}$ ) has an inductance of $1.03 \mathrm{mH}$ with an internal resistance of $0.5 \Omega$. The capacitor used has a capacitance of $435 \mu \mathrm{F}$ and a maximum voltage of $400 \mathrm{~V}$. The active switches are implemented using MOSFET (FCH023N65S3) with an internal resistance of $18 \mathrm{~m} \Omega$, and an ultrafast diode MUR1560G is also used in this topology with a voltage drop of $0.6 \mathrm{~V}$ with an internal resistance of $18.4 \mathrm{~m} \Omega$. The control circuit used for the converter consists of a DC power supply, four TLP350 gate drivers to activate the MOSFETs, a LEM LA 50 $\mathrm{P}$ current sensor, and a micro-controller in the form of Arduino Due. DC power supply with 15 Volt output which becomes the gate driver input voltage. The gate driver gets input from the Arduino and the power supply to be able to generate a PWM waveform which is used to activate the mosfet. Arduino due is used to control a new simplified four-phase two-cascade converter in a closed loop with the actual current input obtained from the detection results of the LEM LA $50 \mathrm{P}$ current sensor and then compared to the reference. In the experiments, controller performance also tested for three conditions, variation in the current reference, load resistance and source voltage. 

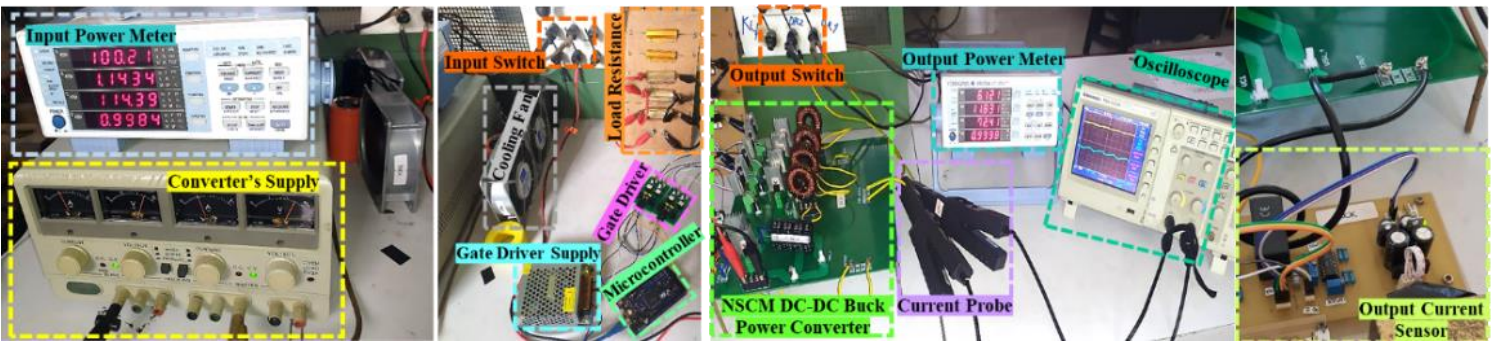

Figure 7. Experimental setup

\subsection{Case I, variation in the current reference}

The experiment result in Figure 8 shows the waveforms of actual output current $\left(\mathrm{I}_{\mathrm{o}_{-}}\right.$Actual $)$and the reference output current $\left(I_{\circ \_}\right.$Reference). The output current is expected to follow the reference pattern even if the reference pattern changes. From the experiment that has been carried out, it can be seen that the actual current still can follow the reference current even though the reference current fluctuates from 22 to 16 Ampere or vice versa.

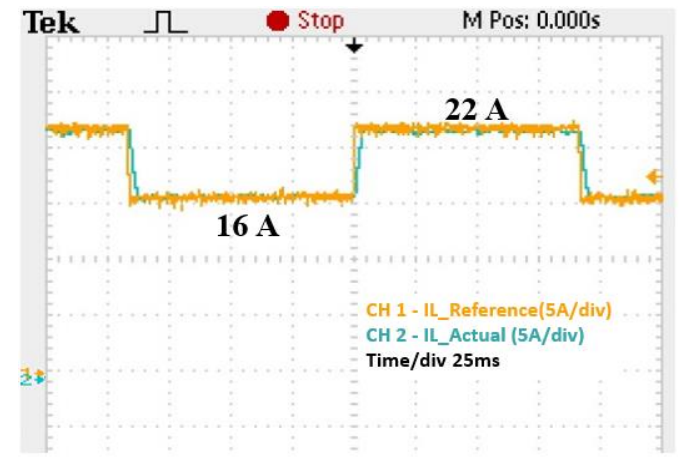

Figure 8. Experimental result for the reference current variation

\subsection{Case II, variation in the load resistance}

Figure 9 shows the waveforms of actual output current ( $\mathrm{I}_{\mathrm{o} \_}$Actual), and reference output current ( $\mathrm{I}_{\mathrm{o}}$ Reference) during a load resistance change. From the experiment that has been carried out, it can be seen that the actual current still can follow the reference current in 16 Ampere even though the load resistance fluctuates from 0.14 to $0.213 \Omega$ or vice versa. In other words, the current controller is running as expected.

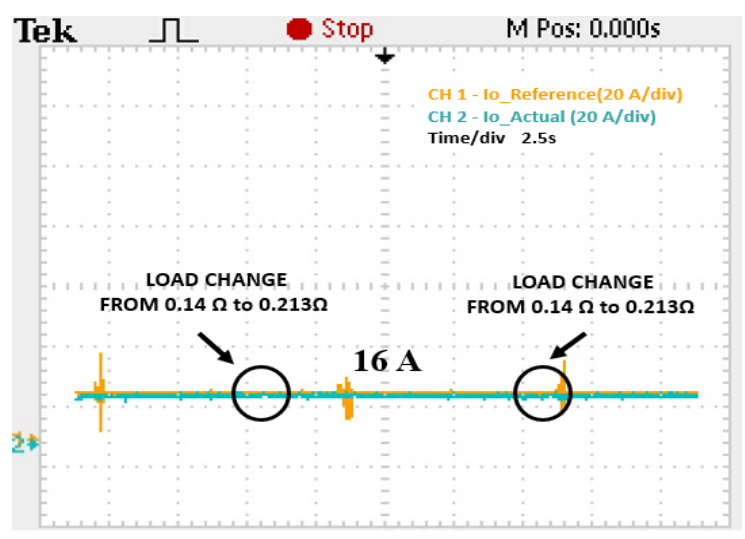

Figure 9. Experimental result for the load resistance variation 


\subsection{Case III, variation in the source voltage}

The experiment results in Figures 10 (a) and (b) show the waveforms of input voltage (Ed), actual output current $\left(\mathrm{I}_{\mathrm{o}_{-}}\right.$Actual $)$and reference output current $\left(\mathrm{I}_{\mathrm{o}}\right.$ Reference). The actual output current is expected to follow the reference pattern even if the source voltage changes. From the experiments that have been carried out, it can be seen from Figures 10 (a) and (b) that the actual output current still can follow the reference current in 16 Ampere even though the source fluctuates, either increasing or decreasing.

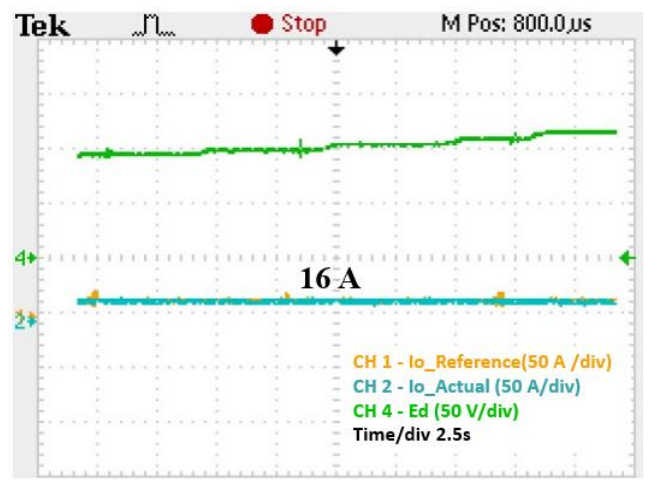

(a)

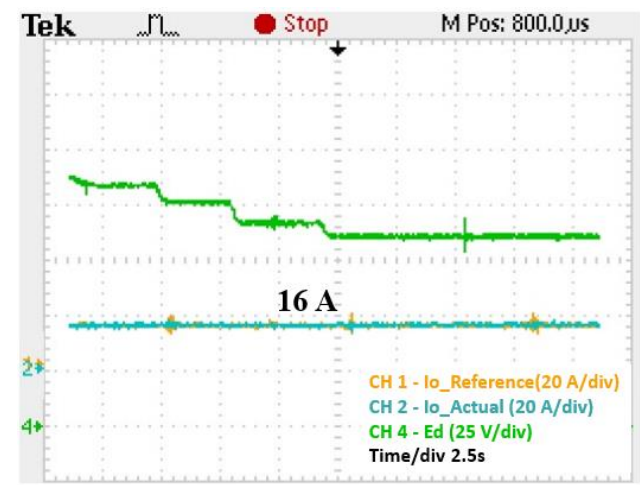

(b)

Figure 10. Experimental result for the source voltage variation: (a) increasing, (b) decreasing

\section{CONCLUSION}

A current control method for a new simplified cascade multiphase DC-DC buck converter has been proposed in this paper. In order to design the current controller, the small-signal model of the proposed converter was derived. Simulated and experimental results are used to verify the performance of the proposed current controller. Robustness of the current controller under various disturbances are verified. This current controller is useful to control the output current of the proposed converter for various applications.

\section{ACKNOWLEDGEMENTS}

The authors wish to thank the Korea Midland Power Company for partially funding this research.

\section{REFERENCES}

[1] M. G. Fontana, Corrosion Engineering, McGraw-Hill International Edition, Third Edition, pp 1-4, 1987.

[2] NACE International, "Control of External Corrosion on Underground or Submerged Metallic Piping Systems, Engineering 360, pp. 1-33, 1997.

[3] NACE International, "Standard recommended practice: design, installation, operation, and maintenance of impressed current deep ground beds," Engineering 360, pp. 1-19, 2001.

[4] S. A. H. Mohammed and I. M. Abdulbaqi, "Numerical Study and Design of an Impressed Current Cathodic Protection System for Buried Metallic Pipes," 2018 Third Scientific Conference of Electrical Engineering (SCEE), 2018, pp. 95-100, doi: 10.1109/SCEE.2018.8684076.

[5] S. S. Varghese and S. George, "Analysis of AC-DC Converter Based on Power Factor and THD," International Journal Emerging Technology and Advance Engineering, vol. 3, no. 2, pp. 350-356, February 2013.

[6] A. B. Ganesen, N. Prameswari, F. K. Nuraziz, A. Rizqiawan, and P. A. Dahono, "Simplified Cascade Multiphase DC-DC Power Converter for Low Voltage Large Current Applications: part --- steady-state analysis," International Journal of Power Electronics and Drive Systems (IJPEDS), vol. 12, no. 3, pp. 1708-1719, September 2021, doi: 10.11591/ijpeds.v12.i3.pp1708-1719.

[7] P. A. Dahono, "Simplified cascade multiphase DC-DC boost power converters for high voltage-gain and low-ripple applications," International Journal of Power Electronics and Drive Systems (IJPEDS), vol. 12, no. 1, pp. 273-285, March 2021, doi: 10.11591/ijpeds.v12.i1.pp273-285.

[8] V. Vorperian, "Simplified analysis of PWM converters using model of PWM switch. II. Discontinuous conduction mode," in IEEE Transactions on Aerospace and Electronic Systems, vol. 26, no. 3, pp. 497-505, May 1990, doi: 10.1109/7.106127.

[9] J. Mahdavi, A. Emaadi, M. D. Bellar, and M. Ehsani, "Analysis of power electronic converters using the generalized state-space averaging approach," in IEEE Transactions on Circuits and Systems I: Fundamental Theory and Applications, vol. 44, no. 8, pp. 767-770, August 1997, doi: 10.1109/81.611275. 
[10] K. Natarajan and M. Yektaii, "Modeling of DC-DC Buck Converters for Large-Signal Frequency Response and Limit Cycles," in IEEE Transactions on Circuits and Systems II: Express Briefs, vol. 53, no. 8, pp. 712-716, August 2006, doi: 10.1109/TCSII.2006.876380.

[11] R. D. Middlebrook, "Small-signal modeling of pulse-width modulated switched-mode power converters," in Proceedings of the IEEE, vol. 76, no. 4, pp. 343-354, April 1988, doi: 10.1109/5.4421.

[12] X. Li, X. Ruan, Q. Jin, M. Sha, and C. K. Tse, "Small-Signal Models with Extended Frequency Range for DC-DC Converters with Large Modulation Ripple Amplitude," in IEEE Transactions on Power Electronics, vol. 33, no. 9, pp. 8151-8163, Sept. 2018, doi: 10.1109/TPEL.2017.2773641.

[13] R. D. Middlebrook, and S. Cuk, "A general unified approach to modelling switching-converter power stages," 1976 IEEE Power Electronics Specialists Conference, 1976, pp. 18-34, doi: 10.1109/PESC.1976.7072895.

[14] Q. He, and Y. Zhao, "The design of controller of buck converter," 2010 International Conference on Computer Application and System Modeling (ICCASM 2010), 2010, pp. V15-251-V15-255, doi: 10.1109/ICCASM.2010.5622609.

[15] H. Sira-Ramírez, A. Luviano-Juárez, and J. Cortés-Romero, "Robust input-output sliding mode control of the buck converter," Control Engineering Practice, vol. 21, no. 5, pp. 671-678, May 2013, doi: 10.1016/j.conengprac.2012.03.008.

[16] A. Kugi, and K. Schlacher, "Nonlinear H/sub /spl infin// controller design for a DC-to-DC power converter," in IEEE Transactions on Control Systems Technology, vol. 7, no. 2, pp. 230-237, March 1999, doi: $10.1109 / 87.748149$

[17] T. Sato, T. Nabeshima, K. Nishijima, and T. Nakano, "DC-DC Converters with a Novel Hysteretic PWM Controller," IECON 2006-32nd Annual Conference on IEEE Industrial Electronics, 2006, pp. 2729-2733, doi: 10.1109/IECON.2006.348061.

[18] S. Maity, and Y. Suraj, "Analysis and Modeling of an FFHC-Controlled DC-DC Buck Converter Suitable for Wide Range of Operating Conditions," in IEEE Transactions on Power Electronics, vol. 27, no. 12, pp. 4914-4924, Dec. 2012, doi: 10.1109/TPEL.2012.2193620.

[19] K. Swathy, S. Jantre, Y. Jadhav, S. M. Labde, and P. Kadam, "Design and Hardware Implementation of Closed Loop Buck Converter Using Fuzzy Logic Controller," 2018 Second International Conference on Electronics, Communication and Aerospace Technology (ICECA), 2018, pp. 175-180, doi: 10.1109/ICECA.2018.8474570.

[20] K. M. Smedley, and S. Cuk, "One-cycle control of switching converters," in IEEE Transactions on Power Electronics, vol. 10, no. 6, pp. 625-633, Nov. 1995, doi: 10.1109/63.471281.

[21] D. Maksimovic, Y. Jang, and R. W. Erickson, "Nonlinear-carrier control for high-power-factor boost rectifiers," in IEEE Transactions on Power Electronics, vol. 11, no. 4, pp. 578-584, July 1996, doi: 10.1109/63.506123.

[22] P. Cominos, and N. Munro, "PID controllers: Recent tuning methods and design to specification," IEE Proceedings: Control Theory and Applications, vol. 149, no. 1, pp. 46-53, January 2002, doi: 10.1049/ipcta:20020103.

[23] R. Matusu, "Calculation of all stabilizing PI and PID controllers," International Journal of Mathematics and Computers in Simulation vol. 5, no. 3, pp. 224-231, 2011.

[24] R. Kurokawa, T. Sato, R. Vilanova, and Y. Konishi, "Closed-loop Data-driven Trade-off PID Control Design," IFAC-PapersOnLine, vol. 51, no. 4, pp. 244-249, January 2018, doi: 10.1016/j.ifacol.2018.06.073.

[25] U. R. Prasanna, and A. K. Rathore, "Two loop average current control implementation using cypress PSoC with closed loop experimental results," 2013 IEEE Energy Conversion Congress and Exposition, 2013, pp. 4199-4206, doi: 10.1109/ECCE.2013.6647260.

[26] K. Ogata, "Modern control engineering," Fifth Edition. Prentice Hall, 2010.

[27] M. M. Garg, Y. V. Hote, and M. K. Pathak, "Design and Performance Analysis of a PWM dc-dc Buck Converter Using PI-Lead Compensator," Arabian Journal for Science and Engineering, vol. 40, no. 12, pp. 3607-3626, December 2015, doi: 10.1007/s13369-015-1838-z.

[28] N. Tan, I. Kaya, C. Yeroglu, and D. P. Atherton, "Computation of stabilizing PI and PID controllers using the stability boundary locus," Energy Conversion and Management, vol. 47, no. 18-19, pp. 3045-3058, November 2006, doi: 10.1016/j.enconman.2006.03.022.

\section{BIOGRAPHIES OF AUTHORS}

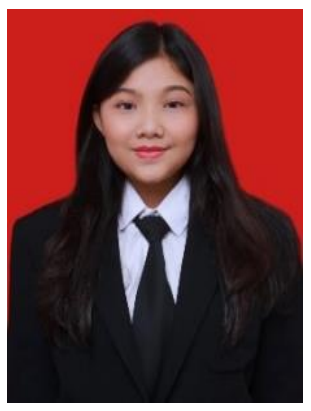

Nungky Prameswari was born in Bandung, Indonesia in 1996. She received the bachelor's degree in Electrical Engineering in 2018 from Universitas Diponegoro, Indonesia. Her fields of research are power electronics and drive systems. She has interest in power engineering and power electronics. At present, she is a graduate student at the Institut Teknologi Bandung, Indonesia. Email: nungkyprameswari24@gmail.com. Google scholar: Nungky Prameswari 

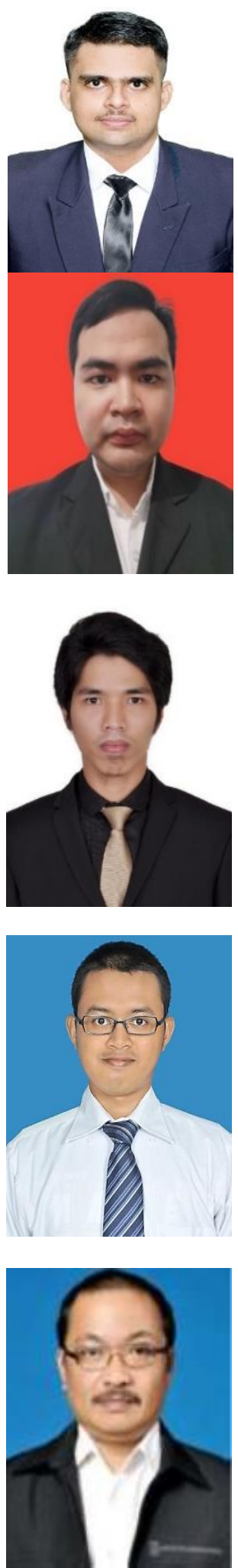

Anand Bannet Ganesen, He received his bachelor's degree in Electrical Engineering from Institut Teknologi Bandung, Indonesia, in 2020. His fields of research are power electronics and drive systems. He has interest in power systems and power qualities. At present, he is a graduate student at the Institut Teknologi Bandung, Indonesia. Email: anandbannetganesen@gmail.com. Google scholar: Anand Bannet Ganesen.

Falah Kharisma Nuraziz was born in Bandung, Indonesia in 2000. His field of research is power electronics. He has an interest in electrical power engineering and power electronics. At present, he is an undergraduate student at the Institut Teknologi Bandung Indonesia. Email: falahkharismanuraziz@gmail.com. Google scholar: Falah Kharisma Nuraziz.

Jihad Furqani, was born in Malang, East Java, Indonesia in 1990. He received B.S. degree in Electrical Power Engineering from Bandung Institute of Technology in 2012. He received M.S. degree in Electrical Engineering from Bandung Institute of Technology in 2013. He received Dr. Eng degree in Electrical and Electronic Engineering from Tokyo Institute of Technology in 2019. He has been studying multilevel and multiphase motor drive, noise reduction in switched reluctance motor, power electronic converter for renewable energy application, and electric motor for vehicle application. He was Visiting Researcher of University of Akron in 2017 and Visiting Lecture of Tokyo Institute of Technology in 2021. Currently, he is lecturer in Electrical Power Engineering, School of Electrical Engineering and Informatics, and National Center for Sustainable Transportation Technology, Bandung Institute of Technology. He received IEEE Star Reviewer in 2019. Email: j.furqani@konversi.ee.itb.ac.id. Google scholar: Jihad Furqani.

Arwindra Rizqiawan, He received his bachelor and master's degree from Insititut Teknologi Bandung, Indonesia, in 2006 and 2008, respectively, and doctoral degree from Shibaura Insitute of Technology, Japan, in 2012, all in the field of electrical engineering. His current main interests are power engineering, power electronics, and renewable energy. He is currently serving as assistant professor in School of Electrical Engineering and Informatics, Institut Teknologi Bandung, Indonesia. He is certified professional engineer (IPM) in Indonesia by the Institution of Engineers Indonesia (PII), and ASEAN Engineer by ASEAN Engineering Register. Email: windra@stei.itb.ac.id. Google scholar: Arwindra Rizqiawan.

Pekik Argo Dahono got the Insinyur (Ir) degree, from the Institut Teknologi Bandung, Indonesia, in 1985, the Master and Doctor Engineering degrees from Tokyo Institute of Technology, Japan, in 1992 and 1995, respectively, all in electrical engineering. He is registered as a Professional Engineer in Indonesia and ASEAN. He is a senior member of IEEE. He is cofounder of Indonesia Smart Grid Initiatives and Indonesia Power Quality Initiatives. At present, he is a professor in the School of Electrical Engineering and Informatics, Institut Teknologi Bandung. He has interest in power electronics, power systems, and power quality. Email: padahono@ieee.org. Google scholar: Pekik Argo Dahono. 